\title{
Thug Life: significados sobre masculinidad y trasgresión en el rap malandro
}

\author{
Antonio de Jesús Barragán Bórquez \\ xntonio@hotmail.es \\ Centro de Investigación en Alimentación y Desarrollo (CIAD, A.C).
}

\section{Resumen}

En este artículo se exploran y describen, desde la perspectiva estructural-constructivista de la masculinidad y la criminología cultural, las diversas formas en que se resuelve ser hombrejoven en un contexto de violencia y delincuencia bosquejadas en el universo simbólico del rap malandro de tres ciudades del norte mexicano, Hermosillo, Guaymas y Obregón, del estado de Sonora. Mediante el análisis de contenido de nueve canciones se encontró que las narrativas sobre el sentido del barrio, la búsqueda de respeto, la dinámica de las drogas ilegales, la postura corporal y el rap como práctica, además de integrar una crónica realista de la condición juvenil en el margen, también plantean valores que son muy apreciados por nuestra sociedad, como orgullo, reputación, lealtad, esperanza, solidaridad, honestidad, reciprocidad, resistencia y adaptación. Esto constituye al rap malandro como un fenómeno que expresa coherencia con el tiempo y lugar en que se inscribe, más allá de los estigmas y censuras.

\section{Palabras Clave}

cultura popular, juventud urbana, violencia, música contemporánea, análisis cualitativo. 


\title{
Thug Life: meanings about masculinity and transgression in malandro rap
}

\begin{abstract}
This article explores and describes, from the structural-constructivist perspective of masculinity and cultural criminology, the various ways in which it is resolved to be manyoung in a context of violence and crime outlined in the symbolic universe of malandro rap from three cities in northern Mexico, Hermosillo, Guaymas y Obregón, from Sonora state. By analyzing the content of nine songs, it was found that narratives about the sense of neighborhood, the search for respect, the dynamics of illegal drugs, body posture and rap as a practice, as well as integrating a realistic chronicle of youth status into the margin, also raise values that are highly appreciated by our society, such as: pride, reputation, loyalty, hope, solidarity, honesty, reciprocity, endurance and adaptation. This constitutes the malandro rap as a phenomenon that expresses coherence with the time and place in which is inscribed, beyond stigmas and censorship.
\end{abstract}

\section{Key Words}

popular culture, urban youth, violence, contemporary music, qualitative analysis.

\section{Introducción}

La música es considerada una actividad de comunicación e interacción humana muy importante, pues los usos, funciones y posibilidades han sido enormes desde tiempos inmemoriales. Sin embargo, el hecho musical como objeto de estudio de la sociología es entendido por el conjunto de relaciones que lo sostienen y por la capacidad de lograr identidad social (Hormigos, 2012). El rap de pandillas o rap malandro se constituye, en la sociedad moderna y en el amplio abanico de expresiones, como uno de los géneros musicales populares más polémicos de la historia y el que mayor reacción negativa provoca (Canton, 2006; Fried, 1999; Hunnicutt \& Andrews, 2009). Por ello, este trabajo se enfoca en las narrativas líricas que figuran en torno a los significados de ser hombre joven en la ficción épica de la violencia y delincuencia urbana, y la forma en que tales significados se ligan con emociones, prácticas y estrategias que deben ser leídas en contexto.

Desde la lectura de Gilberto Giménez (2005) se entiende al rap malandro como un fenómeno cultural en tanto que produce, transforma y negocia significados, además de tener una función de representación y orientación para la práctica 
individual y colectiva, con capacidad instrumental de crear movimientos juveniles que dan testimonio del modo de cómo estos se apropian del mundo y sus significados (Reguillo, 2000). El rap malandro en México, a diferencia de Estados Unidos y su singular cultura pandillera, alude a una descripción de los estilos de vida de los llamados grupos de esquina (Marcial \& Vizcarra, 2017), entendidos como universos simbólicos de la organización solidaria de la vida juvenil que se reproduce en las zonas urbanas empobrecidas en forma de pandillas, crews o barrios, y que en los últimos años han presentado transformaciones cualitativas que distinguen una nueva escuela de una vieja escuela, asumiendo que ello repercute en la estética del rap malandro que se hace a nivel de barrio y ciudad.

De forma concreta, las preguntas que guían este trabajo son: ¿cuáles son los temas y categorías más relevantes que se encuentran en la lírica del rap malandro? ¿De qué forma se describen los modelos masculinos, y los contextos y situaciones criminógenas? ¿Cómo se relacionan los significados y sistemas valorativos con las condiciones de vida de las ciudades actuales? ¿Cuáles son los aportes y trasgresiones sociales que se proponen? ¿Cuál es el aprendizaje colectivo o aporte positivo de este subgénero?

\section{Origen y desarrollo del rap malandro: la cultura hip hop}

Los teóricos de la juventud y del hip hop indican que este movimiento cultural se gesta en la década de 1970 en los barrios marginados del sur del Bronx en Nueva York, como resultado de los cambios sociales y políticos de la época (Rose, 1989; Marcial, 2006; Persaud, 2011), entre los que destacan la migración de negros caribeños, la política de urbanización, guetización y la multietnicidad. Estos cambios configuraron las condiciones precarias en un terreno urbano tecnológicamente sofisticado, donde el rap y hip hop se convirtió en una dinámica de resistencia para los jóvenes negros de la clase trabajadora que elaboraban rituales festivos improvisados en cualquier sitio (plazas, estacionamientos, casas privadas, locales de fiestas, sótanos, calles y cuadras). Rápidamente, tales prácticas se expandieron al resto de zonas marginadas como Harlem, Queens y Brooklyn.

El hip hop surge como producto de la cultura del haz̧o tú mismo, donde las fiestas con el tiempo establecieron los cuatro pilares del hip hop: grafiti, rap, disc jockey y break dance. Cada componente se traduce en un estilo de expresión artística visual, vocal, musical y corporal. Es una cultura netamente urbana emergida en condiciones de vida particulares. En este caso, el reconocimiento comercial del hip hop, y en específico de su musicalidad, se obtuvo a partir del éxito "Rapper's Delight" de la agrupación Sugarhill Gang de 1979. En esa primera generación la lírica romantizaba el ocio y las condiciones de la vida en la marginación de las comunidades de color. Un par de años después verían la luz grupos como Public 
Enemy, quienes practicaban el llamado rap consciente, retomando una crítica política de la vida cotidiana.

Tricia Rose (2008) indica que el hip hop desde la década de 1980 sufrió una bipergangstarización que es paralela al ascenso de las ventas en la industria de la música y la radio, proceso atravesado por el consumo de la imagen de la vida del gueto de color por la juventud blanca y por la censura de esos estereotipos. También indica que el rap pandillero surgió como la expresión más rentable del hip hop, donde -a finales de lo la década de 1980 en Los Ángeles- grupos pioneros como N.W.A. (acrónimo de niggaz wit attitudes) reflejaban los cambios experimentados por la sociedad de esa época: desempleo crónico en las comunidades negras y marrones debido a la desindustrialización, pérdida de la vivienda y reconfiguración urbana, expansión del comercio de drogas que incluye la aparición de drogas baratas y adictivas como el crack, el deterioro de la salud pública de esas comunidades y la democratización del armamentismo, que se tradujo en el acceso de armas de grueso calibre por parte de la sociedad civil. Es decir, se produjo la configuración de una realidad caótica de la cotidianidad urbana. En 1986 fue publicado "6 n da morning” de Ice T, lo que develaría el rap de la costa oeste en Los Ángeles, dando surgimiento al llamado gangsta rap. Es también en Los Ángeles que las convergencias de la vida cotidiana en el racismo y la marginación de las comunidades de color desembocan en el rap chicano, cuyos orígenes provienen del rap pandillero, siendo Kid Frost con su tema "La Raza" de 1990 el precursor, un año después saldría el grupo Cypress Hill, quienes reforzarían la cultura de la marihuana y lowrider en el rap chicano y gangero, y en el hip hop en general (McFarland, 2006). Propiamente, es de estas comunidades (negras y latinas) donde han surgido los principales exponentes de la industria.

El subgénero del rap pandillero en un inicio retomó la experiencia de la vida callejera en el contexto de las pandillas, aludiendo principalmente a la violencia social y personal, la relación con las agencias de control social (policía, sistema carcelario), las economías ilegales de drogas y mercados sexuales, así como el uso de armas y el sentido de pertenencia al grupo social, logrando reproducir imágenes, música y estilos particulares, es decir, la creación de una estética.

De toda la cultura hip hop, fue el gangsta rap el que llamó la atención y crítica pública, siendo objeto de reiterada censura y logrando un estatus controversial por la temática y crudeza de su letras, que de cierto modo atacaban los valores del sistema de justicia estadounidense, pues las comunidades afroamericanas y latinas dominaban la cultura popular y las cárceles (Pond Cummings, 2010; Schneider, 2011).

El gangsta rap también es conocido como rap criminal o rap malandro y/o cholero en México. Aunque las líneas que los distinguen no parecen ser claras 
pues parecen referirse al mismo discurso. En éste subgénero caben artistas clásicos como 2pac Shakur, Wu Tang Clan, Notorius Big, Bone Thugs N Harmony o Snoop Dogg, hasta Jay-Z o 50 Cent en la década del 2000. Aunque existen muchos subgéneros, es el rap que alude a descripciones de las condiciones de vida en la delincuencia uno de los pilares en el campo del hip hop.

\section{Desarrollo del Rap en México y Sonora}

En algunos países de habla hispana como España, Venezuela y México, los cómicos fueron los primeros personajes en rapear, haciendo una versión adaptada de "Rapper's Delight". En 1981 Memo Ríos fue pionero en el país, y ya para 1991 surgiría la agrupación Caló, conocida como el Vanilla Ice latino, dando pauta a la etapa del rap bailable, logrando gran popularidad y configurándose así el rap comercial. Sin embargo, es también al inicio de la década de 1990 cuando el rap subterráneo o underground emerge, donde artistas como 4to del Tren y Sindicato del Terror fueron considerados los más avanzados del género en México (GarcíaMichel, 2019). En esta época, al rap como producto comercial de masas debe diferenciársele del rap como movimiento cultural, reminiscencia del auténtico hip hop que reclama su creatividad al origen callejero y cotidiano (do it yourself) en el contexto del barrio marginado.

De ese modo, la llegada del rap a México coincide con los procesos de privatización del sector público, así como también con una enorme crisis económica y devaluación de la moneda, con un incremento notable de la industria maquiladora en el norte del país, y con la llegada de drogas sintéticas como la metanfetamina (cristal, ice, foco), es decir, con los procesos negativos de la globalización y neoliberalismo, impactando en las relaciones laborales y familiares, auspiciando un sentimiento de incertidumbre (Bauman, 2011). De alguna manera, las condiciones de vida de las ciudades mexicanas eran óptimas para el surgimiento del rap underground y malandro (pandillero), pues se tenía la posibilidad de experimentar una realidad urbana caótica y hablar sobre ello.

En ese contexto, sería la agrupación de Monterrey (Nuevo León), Control Machete, durante la segunda mitad de la década de 1990 quienes catapultarían el rap mexicano a nivel nacional e internacional, retomando la lírica callejera y pandillera en canciones como "Comprendes Méndez" o "Sí señor". Hasta ese entonces el rap mexicano había permanecido designado a nivel de vecindario local (Tickner, 2008). En ese proceso de desarrollo del subgénero habían surgido agrupaciones como Sociedad Café o Cartel de Santa, así también Dyablo, C4, Akwid o Kartel de las Calles en Tijuana en la primera década de los 2000.

El rap mexicano es un campo complejo en el que artistas como C-kan, Big Flow Music, Kinto Sol, Santa Fe Klan, Alemán o Santa Grifa se han posicionado 
en las altas esferas del rap nacional en los últimos años. Por otra parte, en México también han surgido otras vertientes, como el rap consciente o social (Schott, 2015), el rap feminista (Diez, 2016; Silva, 2017) o incluso el rap indígena (Doncel \& Talancón, 2017), quienes de alguna forma realizan una crítica a la estructura social mexicana por su racismo y desigualdad, aunque son expresiones minoritarias en el campo del rap.

Por otra parte, es a finales de la década de 1990 cuando el rap se reproduce oficialmente en Sonora. Agrupaciones como Atake FDD en Hermosillo y O.M.W (acrónimo de Obregón Most Wanted) de Ciudad Obregón, a principios de los 2000 concretaron sus primeras producciones en las que describían los arquetipos de la fiesta, la amistad y la vida urbana (Ríos, 2019). En esa efervescencia surgieron otros exponentes como Kafe con Leshe, Simpson A huevo, Dilettantes, South Side Kings, Obson Clan, o Vicky MC de Obregón, así como 2 en Clica, Reyes Sin Korona y 6 elementos en Guaymas. Cabe destacar que ya entrado el presente siglo también se produjo un rap de influencia más europea y española, caracterizando el sonido del rap romántico. Por otra parte las batallas de rap y el freestyle han tomado notoriedad, haciendo a la escena rapera en Sonora un campo diverso y fructífero.

De forma circunstancial, en los últimos diez años el trap ha tenido un impacto importante en la cultura hip hop de forma generalizada. Este género se distingue por el uso de música electrónica (techno rap, de ahí algunas hipótesis sobre su terminología: T-rap), por melodías en tonos menores para hacer una atmósfera lúgubre, por bajos más altos, como así también por la influencia del término tram$p a$ (proveniente de atrapamiento, trap en inglés), que se refiere a un estilo de vida inmoral y de excesos marcado por dinero, drogas, mujeres, historias criminales y otras de la vida real, de asenso rápido en la escala social y del éxito (Kaluza, 2018), tal como lo proponía el gangsta rap en sus inicios pero con sonidos más frescos influenciados por la cultura reggaetón y el autotune (efectos vocales).

Este estudio se enfoca en producciones de la última década, considerando y evidenciando las transformaciones que proponen los cambios generacionales.

\section{Marco teórico}

En la década de los noventas del siglo pasado se concretizaron dos escuelas importantes del pensamiento social: por un lado, la ciencia de las masculinidades y, por el otro, la criminología cultural. Estas dos escuelas, entienden a la masculinidad y al crimen -en términos simples y desde una óptica más apegada al estructural-constructivismo- como fenómenos productores de significado dependientes de tiempo y espacio (Núñez Noriega, 2016; Ferrell, 1999). A continuación se describen ambas corrientes. 


\section{Masculinidades o la hombría como objeto de estudio de género}

Los estudios de género de los hombres indican que lo masculino es un elemento del mundo humano que varía de una sociedad a otra y de un tiempo a otro. Tal epistemología descansa en los desarrollos realizados por el feminismo, la teoría crítica, el funcional-estructuralismo, el psicoanálisis y la etnografía antropológica de buena parte del siglo XX, arguyéndose así que la naturaleza de lo masculino es relacional (Connell, 2003), pues implica un proceso donde el sujeto construye su identidad como hombre en interacción con otros hombres y con las mujeres.

El marco de abstracción en el que se lee la masculinidad es el de las construcciones sociales de género, es decir, a partir de la forma en que la sociedad ejerce procedimientos sobre los cuerpos biológicos de las personas (Valenzuela-Arce, 2004). El sistema sexo-género es una forma de organizar el sentido de los cuerpos dentro de un ente social (Rubin, 1986), con la particularidad de que en términos históricos esos sistemas de género han sido binarios, pues oponen el hombre a la mujer, lo masculino a lo femenino y la razón a la intuición, respondiendo más bien a un orden jerárquico que permea a todo el cuerpo social (Conway, Borque \& Scott, 2013). En ese sentido, la masculinidad es una forma de configurar el género en una sociedad, de ordenar el poder en las prácticas, significados y representaciones sociales. La masculinidad es más una creencia que una esencia, es una práctica cargada de significado.

De forma concreta, aquí se entiende a la hombría y a la masculinidad como

un conjunto de significados que participan en la construcción de lo real, en la medida en que, bajo esas concepciones de la hombría o masculinidad, esto es, bajo las concepciones de género, se socializan seres humanos particulares [de ese modo] ...lo que le interesa (a los estudios de los hombres y las masculinidades) es conocer los procesos de significación que instituyen lo masculino, la masculinidad y la hombría en los diversos ámbitos de la vida de los sujetos y de la sociedad, con la consecuencia de configurar identidades, subjetividades, prácticas, relaciones sociales diversas, incluyendo relaciones de poder y resistencia entre las personas y en el cuerpo social todo (Núñez Noriega, 2016, pp. 26-27).

\section{Criminología cultural o la búsqueda del significado trasgresor}

El objetivo principal de esta escuela del pensamiento criminológico es el de comprender cómo los procesos mediados de producción cultural constituyen la experiencia del crimen, del yo y de la sociedad en condiciones de modernidad tardía (Ferrell, Hayward \& Young, 2008). Desde ese planteamiento, el crimen, la desviación y el control del delito son parte de un proceso vinculado a significados 
culturales, simbolismos compartidos e interpretaciones colectivas (Frederick \& Larruskain, 2015).

Tal forma de aproximarse a la realidad se debe a los avances de los estudios culturales de la década de 1970, la criminología crítica, el interaccionismo simbólico, la fenomenología de la desviación, la etnometodología y al pensamiento posmoderno (Ferrell, 1999). Así, el crimen y el control social son una experiencia de la interacción humana, y los significados de lo criminal implican discernir cómo los individuos, grupos y sociedades elaboran y procesan las concepciones que se tiene sobre un símbolo, ya sea un objeto, acto, hecho, cualidad o relación (Geertz, 2003).

Para esta escuela, la mediación del crimen y su impacto en la construcción de la realidad es sumamente relevante, pues la disposición de imágenes, noticias, literatura, cine, música y arte configuran los significados de las representaciones sociales del crimen y su control (Hayward \& Young, 2004). El análisis de iconos y símbolos culturales mercantilizados por medios formales e informales y el hecho de que configuren una cultura del crimen o de la conformidad son aspectos innovadores de esta criminología estética (Carvalho, 2010). Conceptos como la pluralidad y diversidad, crisis y cambios sociales de la modernidad, entre los que se encuentra el universo criminal, son considerados fenómenos de ruptura social que no sólo producen enojo, ira, frustración o impotencia, sino también fascinación y atracción, que aluden a un orden ambivalente de su representación social y significado, insertos en una estructura valorativa y afectiva vigente (Tonkonoff, 2011) que posibilitan los límites de las prohibiciones, resistencias y prácticas culturales creativas.

De forma general, el crimen y la masculinidad son elementos relevantes para el campo académico en tanto que producen significados en el espacio social, y con ello, realidad. Masculinidad y crimen se refieren a significados y prácticas de los sujetos que regularmente son sometidos a evaluaciones sociales.

\section{Método}

Utilizando el análisis cualitativo de contenido de Cáceres (2003) esta investigación se inscribe dentro del alcance descriptivo-interpretativo. Para esto, las unidades de análisis comprenden los enunciados contenidos en las canciones, entendiéndose por enunciado como un conjunto de signos producto de la actuación y formulación lingüística que le permiten estar en relación con un dominio de objetos, posicionar a todo sujeto posible, situarse entre otras actuaciones verbales y dotarse de una materialidad repetible (Foucault, 2002a).

Para el análisis, se seleccionó una muestra de nueve canciones de artistas locales de tres ciudades 
sonorenses. De la ciudad de Hermosillo los artistas seleccionados son: Proyecto de Barrio, Doble U Clica, Enfermos Crew, Farck, Sick Brain Crew y La Squina Loca. De la ciudad de Obregón: Spooky, DrimelowCC, Andres CxC y Obregón Familia Klan. Y de Guaymas: Señores Subterráneos, Waysones GDB, Malandro Rekordz, Pelón 33 y Chill A Gang, como se desglosa en la siguiente tabla.

\begin{tabular}{ccccc}
\hline Orden & Artista & Canción & Casa Productora & Año \\
\hline 1 & Proyecto de Barrio & Wasiado marihuano & $\begin{array}{c}\text { Unión de Gangsta } \\
\text { Records }\end{array}$ & 2017 \\
2 & $\begin{array}{c}\text { Doble u Clica feat. Pk crew } \\
\text { (Enfermos Crew) }\end{array}$ & A trecientos cuarenta & Dobleu FPB & 2017 \\
& $\begin{array}{c}\text { Farck feat. Bago NM } \\
\text { (Sick Brain Crew) }\end{array}$ & Problemas & $\begin{array}{c}\text { Farck House / } \\
\text { Sickbraincrew }\end{array}$ & 2020 \\
4 & La Squina Loca & Salgo con la bendición & La Squina 662 & 2019 \\
4 & Waysones GDB feat. EmeGe y & Mi zona & OGs Familia / & 2017 \\
5 & Pelón 33 & RBS & 2010 \\
6 & Señores Subterráneos & Muralla 22 & Kuartel 22 Prods. & 2019 \\
7 & Chill a Gang feat. Spooky & Si la saca la usa & EP Company & 2019 \\
8 & DrimelowCC feat. Andres CxC & Norte de obregón & EBK ENT Recs. & 2019 \\
9 & Obregón Familia Klan 13 & De lo peor & MK Records & 2020 \\
\hline
\end{tabular}

Tabla 1. Información general de las canciones.

La muestra se trata de autoproducciones ${ }^{1}$ y colaboraciones entre varios artistas de la escena local, en la que no todos siguen activos. La estrategia de selección fue a conveniencia, por lo que atiende a un estudio exploratorio y no exhaustivo, pues responde a una muestra conceptual donde el principio de selección se basó en un análisis previo de los contenidos líricos y estéticos de las propuestas según información recopilada durante una exploración en redes sociales (Facebook, YouTube, MySpace, Spotify y SoundCloud). Seis de las nueve canciones poseen video oficial, lo que contribuyó en su selección, pues allí se desarrolla una narrativa no sólo oral sino también visual, sin embargo, el análisis aquí sólo se enfoca sobre el escrito y dicho.

Una vez seleccionado el material, se transcribieron las letras para crear un corpus textual tratando de respetar la intencionalidad y jerga, ya que estas no se encuentran de forma oficial para su acceso público.

Las canciones analizadas fueron "Wasiado marihuano" (LUPE ONE IBARRA, 2017), "A trecientos cuarenta" (W GXNG, 2017), "Problemas" (SICKBRAINCREW SBC, 2020), "Salgo con la bendición” (La Squina Loca 662, 2019),

1. Abarca tanto procesos de grabación, mezcla y masterización, así como distribución, lo que le da cierto estatus de informalidad pues se carece de los canales y circuitos de las grandes producciones de la industria musical y más bien se refiere a un proceso del do it yourself. 
"Mi zona" (Waysones GDB, 2017), "Muralla 22” (FYLS95, 2010), "Si la saca la usa" (CHILL A GANG, 2019), "Norte de obregón” (EBK ENT, 2020) y “De lo peor" (Obregon, Familia, Klan13, 2020).

\section{Hallazgos: los significados del rap malandro}

A continuación se describen los componentes de lo masculino y la trasgresión (violencia y delincuencia) a partir de las cinco categorías más relevantes encontradas en los textos: el sentido del barrio, el cuerpo y su situación, las drogas y su universo, el respeto, y el rap como práctica.

\section{El sentido del barrio}

El barrio representa el espacio desde el que se narra y sobre el que es posible contar cosas. Se concibe a la geografía local por su sentido de criminalidad y marginación evocando a una constante sensación de peligro: robos, consumo, adicciones y tráfico de sustancias ilegales, prácticas de la vida nocturna y del ocio.

Por ejemplo, se describe un peligro permanente y un sentido de advertencia: "vengo a cantarles todo a detalle / las cosas que pasan en todas las calles / piquetes, balazos y puro desmadre" (Waysones GDB, 2017), "pa' que watches cabrón el norte de obregón / bien caliente el terreno reconozcan obson" (EBK ENT, 2020), y "allá en mi barrio, donde poner seguro a todo es la rutina / el que te roba aquí no te discrimina / o le trabajas o le tiras a la esquina / ¿tú por cuál te inclinas?" (CHILL A GANG, 2019). Parte de la dinámica barrial se traduce en una valoración negativa sobre el espacio y sus contenidos, objetos y relaciones sociales, que puede entenderse dentro de un proceso de estigmatización social (Goffman, 2006).

Algunas figuras enunciativas describen una otredad criminógena que coexiste en la realidad barrial: "el wasiado marihuano desmadroso hasta la tumba, el que pica, roba y tumba, (...) son V de V de vándalos, los que en el barrio rifan”" (LUPE ONE IBARRA, 2017), "mis hommies bien prendidos de night / nahuales por doquier, dispuestos para accionar" (W GXNG, 2017), y "muralla 22, un barrio peligroso, aquí sobresalen marihuanos y fachosos" (FYLS95, 2010).

Los enunciados tienden a describir los procesos de las violencias comunes de las comunidades en desventaja. Parte de su sentido de trasgresión enunciativa es la de revictimizar a la comunidad al hablar de los problemas que la afectan: el lado oscuro de la cotidianidad urbana. Entender a las canciones como acontecimientos (Foucault, 2002a) es comprender a una comunidad socializando explícitamente su condición de existencia.

En la misma vena de análisis, encontramos otros enunciados que hablan de 
la visibilización de la relación que una comunidad tiene con las sustancias y los mercados ilegales: "pues yo sigo con los mismos / traficando en mi barrio / son pelotas de perico / no me enreden con el grillo, por traerlo en el bolsillo" (SICKBRAINCREW SBC, 2020), "rolando por el barrio / el gallo se consume lento" (Obregon, Familia, Klan13, 2020), y "en mi barrio cuando se apagan las luces prenden los focos / vienen a desaparecer ya quedan pocos" (CHILL A GANG, 2019).

Es el barrio una entidad social y cultural que representa la ruptura del intento por lograr una apariencia de control dentro de mundos de vida ontológicamente inseguros (Fenwick, 2004). Hablar de la cruda realidad es una ruptura en el lenguaje del contrato social. Y situar el Yo en la perspectiva del criminal es parte de la naturaleza trasgresora del rap.

La vida barrial y callejera también se relaciona con el origen y explicación de un presente, como vivencia y sobrevivencia. El barrio se convierte en una experiencia que atraviesa al sujeto. "La razón de que yo sea un hijo de puta / ahí te va la respuesta a todas tus preguntas / desde que en la esquina este güey se junta, resulta / que ni pa' que te cuento, a lo mejor y te asustas" (La Squina Loca 662, 2019), "crecimos perros y nos formó la calle" (CHILL A GANG, 2019), y "para las invasiones mis canciones de repente / yo nací en una de ellas compa no soy diferente" (LUPE ONE IBARRA, 2017).

El barrio alude a una realidad donde se manifiesta el conflicto social. Es en ese micro ámbito donde se visibiliza el llamado código de la calle (Kubrin, 2005), ese principio que rige el comportamiento en la interacción pública, con la posibilidad de articular normas y relaciones sociales, el cual es caracterizado por la búsqueda de respeto y la violencia como recurso legítimo, además de funcionar como una fuente de identidad y poder para los jóvenes. Es precisamente ese código callejero el que permea toda la narrativa del rap. Sobre ello Jan Jagodzinski (2005) indica que el rap es el mejor ejemplo de la forma en que la subjetividad posmoderna se manifiesta directamente en la letra y en la música.

El sentido del barrio es uno de los pilares identitarios en el rap malandro. $\mathrm{Al}$ barrio se le manda saludos de aprecio y cariño. El sentimiento ambivalente por el barrio es, paradójicamente, un elemento interdiscursivo (Fairclough, 2008) siempre presente en los textos de este género musical. Allí y desde allí se forjan sentidos de amor y odio, de fraternidad y violencia. El barrio es una inscripción en la subjetividad, pues relata una forma de socialización de las personas, de jóvenes y hombres.

\section{El cuerpo y su situación}

Un estado corporal del sujeto recurrente en las narrativas de este subgénero se 
orienta principalmente en describir una postura cognitiva hipermasculina. Desde Foucault (2002b) se arguye que en un contexto adverso se requiere disciplinar el cuerpo para las condiciones de la vida callejera, donde los saberes y poderes del código de la calle articulan tal disciplinamiento.

En los siguientes enunciados el desplazamiento es importante para la interiorización y proyección de confianza: "malandro, malandrote, malandrito, mala cara / camino por el barrio con esta fiera mirada / la clica de la esquina, vándalos, no dicen nada nada / pues saben que la vida mía ha sido reclamada" (LUPE ONE IBARRA, 2017), "salgo con la bendición de mi madre, bien trucha camino si voy por la calle / no miro, ni escucho, ni le doy detalle, si usted no conoce, es mejor que se calle" (La Squina Loca 662, 2019), y "que porque soy de lo peor, por como vivo y como ando / que por donde quiera va caminando tumbado y bien malandro / acto me miran pasar rolando ese gallo con la pinche OFK" (Obregon, Familia, Klan13, 2020).

Desde el interaccionismo simbólico criminológico de Edwin Lemert, se argumenta que una parte del etiquetamiento delictivo del sujeto es la reacción social que existe en ese proceso de significación, al que denomina como desviación secundaria (Orellana Wiarco, 2012). Tal proceso consiste en la evaluación y categorización del sujeto por su adscripción subcultural desviada de la convencionalidad en su carácter de criminal o delincuente: malandro. Desde esa óptica, las narrativas describen una corporalidad desde el margen en la jerarquía social, que aluden a la representación del forajido urbano en torno a la construcción de un sujeto que sale avante de las adversidades que manifiesta la vida callejera de la urbe caótica.

En esa interacción se puede observar que el sujeto despliega una "poética masculina" (Herzfeld, 1985) en la que ciertas formas de ser estar, actuar, decir, sentir o pensar son las adecuadas en la administración del cuerpo y sus sensaciones en un contexto situacional. En esa postura, la regulación de emociones como forma de adaptación resulta interesante, como se demuestra a continuación: "me la viví en el ruedo, todo este tiempo, ahuevo / por eso el chamaco ya ni tiene miedo" (EBK ENT, 2020), "cero paniqueo compa no hay fin / pase lo que pase seguimos haciendo un desmadre" (W GXNG, 2017), "aprendí a cuidarme solo desde que salí pal ruedo / no temo a nada compa, me defiendo, puño y huevos" (La Squina Loca 662, 2019), y "eso a mí no me asusta / que me venga a decir que van sobre mí que va sacar la fusca / morro no sea alucín que aquí quien la saca la usa" (CHILL A GANG, 2019).

El material comprende que las emociones pueden ser irracionales o instrumentales, que tienen un objetivo intencional, son generadas, tienen antecedentes y encausan la acción. Así también conllevan una valoración positiva o negativa (Trajtenberg, 2011). De ese modo deben ser leídas tanto en el contexto como 
en los sujetos que se despliegan. La administración del miedo y la confianza son elementos que articulan el Yo en el contexto de la crónica de los contrastes experimentados en la vida cotidiana. Como se verá más adelante, aparece el sujeto con la capacidad instrumental de negociar su raciocinio y de adaptarse al ambiente, pues las violencias son experiencias que atraviesan al sujeto y sobre las que debe salir adelante.

Los ordenamientos del cuerpo y las sensaciones se orientan en la figuración de una juventud intrépida. Elementos biológicos como la edad traspasan las narrativas de los enunciados, así también la disposición para la confrontación: "la vida es muy corta, por el cuerpo tinta / maldita, es la que dicta, esta adicta / alma sin calma por pecado / suerte se divorció de mi lado" (W GXNG, 2017), "no me rajo estoy dispuesto, bien puesto pa' lo que venga / me soltaron la rienda y no habrá quien me detenga" (SICKBRAINCREW SBC, 2020), "somos fieros, pandilleros, guerrilleros / no te metas a mi gueto, somos un verguero de choleros / peleoneros, bien unidos, a la riña no corremos (...), "a esta zona ni le entre, estamos pendientes / somos pocos pero locos, todos dementes / súbale a la bocina, que valga madre lo que diga la pinche vecina" (Waysones GDB, 2017), y "listos pal desorden y cualquier mandado / sigo siendo el mismo, nunca he cambiado (...), extorsión, loco en la mente y aquí en el corazón” (EBK ENT, 2020).

$\mathrm{Al}$ respecto, Damien Arthur (2006) comenta que el hip hop es un enclave masculino que promulga una actuación demostrativa de ser el más duro, así como de la represión de los rasgos femeninos utilizando burlas sexistas y homofóbicas, pero no contra mujeres y homosexuales sino para feminizar al otro y para masculinizarse a sí mismos. Por ello, los enunciados de la masculinidad deben ser leídos a partir de la forma en que nuestra sociedad configura el género, en este caso patriarcal y machista, donde la estructura social posibilita la configuración de determinadas subjetividades o modos de ser-estar que suscriben identidades juveniles surgidas en la posmodernidad.

Algunas otras narrativas evocan un sentimiento de persistencia, reactividad y de reto ante el otro. Las habilidades relacionadas con la significación del yo en una determinada situación describen una forma de ejecutar la agencia, de ejercer la libertad, la identidad individual y colectiva. "Nunca pararé, nomás por un pendejo que me quiere ver caer" (FYLS95, 2010), "y sobres que este juego hommie es para hombres / Saco la lata y en tu barda pongo mi nombre / Si se hace el tiro culón el que corre / Quiero puro pinche loco que le atore" (EBK ENT, 2020), "haciendo lo que quiero / conecto con quien quiero" (Obregon, Familia, Klan13, 2020), y "si andas hablando mucho, sin pensarla yo te quiebro" (SICKBRAINCREW SBC, 2020).

De forma general, las figuras simbólicas descritas configuran procesos como 
la regulación de emociones, la adaptación al ambiente adverso relativos a la experiencia callejera, el estado de alerta constante, la aceptación de retos, una preparación para la confrontación inmediata y el sentimiento de persistencia y permanencia.

La trasgresión enunciativa del rap es la de narrar la performatividad del cuerpo malandro que procesa situaciones y emociones, y que también las provoca, en el espectador y en el otro. Esa performance masculina puede ser entendida como una forma de cuidar de sí en esas realidades particulares (Foucault, 1999). Desde el racionalismo del control social, el rap que alude al retrato de la violencia estructural e individual que se da en el contexto del conflicto urbano configura un espectáculo donde la búsqueda de riesgo, de placer, de estilo y de empoderamiento son formas de sacar el cuerpo adelante en medio de las exigencias de la modernidad tardía (Lyng, 2004).

\section{Las drogas y su universo}

Lo dicho en torno al consumo de drogas y al estado alterado de consciencia en la cotidianeidad son elementos recurrentes en las enunciaciones del rap. Las principales sustancias referidas suelen ser la marihuana, la cerveza, las pastillas y la metanfetamina. Son vehículos para la interacción e identificación social, retratan la relación con las sustancias y sus efectos: "proyecto para arriba, rolo un bote y una rictra / los ojos bien pachecos y un hambral por tanta grifa" (LUPE ONE IBARRA, 2017), "todo mi cuerpo alterado por culpa de una maldita píldora / la vivimos de película tirando psica-lirica, / escribiendo lo que pasa / rolando varias bachas" (W GXNG, 2017), “de camino pal cantón con todo un caguamón / metiendo pa' califas, nomás prendo el blunt / bien prendido, bien drogado que pongan un cumbión" (EBK ENT, 2020), y "que fluya vato como fluye el humo / que en el cuarto me consumo y empiezo a delirar / a punto de madrugada y pegar otra fumada / pa' que watchen la crema de la OFK" (Obregon, Familia, Klan13, 2020).

Los mercados de las drogas ilegales son parte de la caótica realidad urbana y juvenil ${ }^{2}$, donde los juegos enunciativos se producen en un contexto que abarca décadas de la llamada guerra contra las drogas iniciada por la política exterior de Estados Unidos en México desde la década de 1970, y que desde los noventas

2. En México y Sonora, según informes oficiales de la Encuesta Nacional de Adicciones, Drogas, Alcohol y Tabaco (ENCODAT, 2017) el consumo de drogas ha ido aumentando año con año (para el 2016, el consumo de drogas ilegales había aumentado en $5 \%$ en los últimos ocho años en el estado), donde el perfil general del consumidor de drogas se asocia con: hombres, jóvenes, marihuana, y una situación de empleado. En Sonora el 10\% de la población de 12 a 65 años ha consumido alguna droga ilegal al menos una vez, dicha prevalencia se eleva al $15 \%$ en los hombres, en contraste con $4,9 \%$ en mujeres. 
figuraría como un problema mayor al abrirse los canales no sólo del tráfico internacional sino también de los mercados internos (Valdés Castellanos, 2015). Así, el consumo asociado al narcomenudeo comenzó a ser una problemática de los escenarios urbanos de la ciudad bajo la óptica de una política represiva. Pero, de forma paradójica, estas enunciaciones también se dan en un contexto de reciente apertura al debate institucional del uso recreativo en la despenalización de ciertas drogas, principalmente la marihuana, como parte de las presiones internacionales en la materia. Dichos enunciados hablan de una postura cultural de oposición a la discriminación y represión institucional, así como de la decadencia urbana de las ciudades (Martínez, 1997).

El consumo retratado en las narrativas líricas gira en torno a concepciones ambivalentes. Se lo asocia tanto a procesos criminalizantes (represión policíaca, abuso, cuestiones asociadas a los mercados ilegales circundantes a las sustancias), como a procesos de la vida juvenil, del ocio, de la creatividad, de la festividad, de sus riesgos, problemas y realidades ${ }^{3}$. "A mí ya me da lo mismo si de lunes a domingo me la navego bien pingo / mira como me atizo, me la llevo bien grifo, y si ando elevado al rato le aterrizo" (SICKBRAINCREW SBC, 2020), "fumando y tomando y no hay quien nos pare / waysones locotes, súbale compadre" (Waysones GDB, 2017), "vivo enganchado en las drogas, en un mundo de loquera / viviendo la nueva era, no sabes lo que esperas" (SICKBRAINCREW SBC, 2020), "seguido por la chota siempre fumándole al porro / y sólo en la gota corro, no me importa lo que pase" (La Squina Loca 662, 2019), y "eh buscado un sueño fumándome un leño / me la paso bien risueño, la droga mata el sueño / Viajando entre loqueras nunca me concentro / hasta el momento llegó un presentimiento" (Obregon, Familia, Klan13, 2020).

El significado que adquieren las narrativas en torno a las sustancias ilegales se debe al desarrollo de las pautas de consumo (mayoritariamente juvenil y varonil) y al impacto que ha tenido el mercado de drogas en las ciudades, donde la visibilización del proceso de agudización de los problemas asociados con dichos mercados se asocia a las zonas menos favorecidas, convergiendo elementos de violencia estructural como desempleo, desigualdad y criminalización. Así las figuras enunciativas en torno a las sustancias ilegales son de contraste, algunas se enmarcan

3. Las drogas suelen estar asociados a un gran número de géneros musicales, pues la relación del ser humano con las sustancias es anterior a la industria musical. Géneros como el rock o el pop suelen dar a las sustancias ilegales un papel importante en sus composiciones aunque de forma romantizada, encubierta y sutil, o directa y cruda como en el punk (Fouce, 2003), o el caso de los corridos de traficantes de drogas, que desde la década de 1970 disputó la representación oficial del campo del tráfico de drogas en la esfera pública (Astorga, 1997). Incluso en canciones populares universales como "La cucaracha" se hace alusión a la cultura de la marihuana, cuyo consumo se asoció desde inicios del siglo XX en México con artistas, las clases bajas, el sistema carcelario y sobre todo con las fuerzas castrenses (Vallejo, 2010). 
en el desfogue individual y cohesión social, y otras reflejan la intención de contar parte de la relación entre juventud y drogas ilegales por cómo es: explícita y difícil.

\section{El respeto}

$\mathrm{El}$ respeto en las figuras enunciativas puede comprenderse como un capital simbólico (Bourdieu, 1997), pues aparece como un conjunto de relaciones y atribuciones significantes en el campo de la vida callejera. El respeto aquí es la producción de reconocimiento social: "el respeto lo ha ganado, tiro línea y en la jungla / porque el vato de kilos, ya a cualquiera da una tunda" (LUPE ONE IBARRA, 2017), "el respeto se lo gana el carnalito que respeta / si andan de chapulines se los va llevar la flaca compa, y esto es neta" (W GXNG, 2017), "en la calle me conocen / por respeto, por envidia / no mucha giribilla / eres cholo de mentiras / si me tomo dos tiras / y no monto pantomima" (SICKBRAINCREW SBC, 2020), y "no se meta a esta zona / aquí puro malandro que respeta y no traiciona" (Waysones GDB, 2017).

El respeto se considera un sentimiento que estructura la práctica social, configurando modelos idealizados de la masculinidad (Pitt-Rivers, 1968). El respeto implica una forma de medida de la proximidad social entre los sujetos del grupo, así como con el otro. De forma compleja, las narrativas sobre el respeto describen el proceso de hacerse responsable de sí mismo al asumir los riesgos que la adquisición y el mantenimiento del respeto conllevan en el contexto caótico de la calle y de la masculinidad (De Keijer, 1997). "El respeto a quien las puede y al que no sáquele punta / los locos de mi valle con los falsos no se juntan" (LUPE ONE IBARRA, 2017), "si canto con más ganas es porque muchos me apoyan / la traición y la envidia en la esquina nunca perdonan" (La Squina Loca 662, 2019), y "no me ajeres, no me diga, no me apuntes si no tira / porque lo único que usted dispara son puras mentiras (...), hommie no me quiera verbiar / que es solo aparentar y al final le va dar pa' atrás" (CHILL A GANG, 2019).

La sátira, la burla y el insulto son elementos para justificar la obtención de un bien mayor: recuperar o mantener el honor y la reputación ante la dinámica de una audiencia (Rosen \& Donald, 1999). Valores como la mentira, traición y desconfianza se encuentran muy abajo en la escala valorativa.

De forma general, el respeto es una forma de capital que estructura la acción. Su representación es un elemento discursivo recurrente que narra los procesos de dignificación de la vida callejera.

\section{El rap como práctica}

El rap como proceso creativo cultural es un tema central en las enunciaciones del género. La ejecución oral, la interpretación del rapero y el texto escrito 
configuran formas de capital lingüístico y aspiracional, ya que, por una parte, la reproducción del rap es un fenómeno relevante en sí mismo para las ficciones y, por otra, se mantiene la esperanza de un futuro (Turner, 2019). Recordar al oyente lo que se está haciendo, y el sentido de la práctica es nodal.

Algunos fragmentos se refieren al sentido de perpetuidad: "que me escuche mi gente, y el disco lo reproduzca / un estilo pachecote, mi compa yo sé que les gusta" (LUPE ONE IBARRA, 2017), "que he de morir donde debo y dejar esto de homenaje / y antes de que el tiempo pase buscaré trazar mi huella, pa' que mi nombre se escuche" (La Squina Loca 662, 2019), y "con mi carnal el drimer / para siempre esta rola / así que no abran la boca” (EBK ENT, 2020).

El mensaje como proceso (darlo y producir un efecto) es un evento del que debe quedar constancia. La performance evoca un empoderamiento lingüístico y espacial, donde la ejecución de las letras se centra en describir los significados y posturas al hacer rap.

El reclamo del espacio sonoro para hacer manifiesto determinado mensaje se considera una forma de resistencia simbólica, e inclusive económica, por parte de estos movimientos culturales juveniles en búsqueda de autonomía (Castiblanco, 2005; Olvera 2016). El sentido confrontativo, de autoconfianza y orgullo en la ejecución de la habilidad rapera (que permea todos los subgéneros del rap) tiene que ver con una forma de desplegar la pasión en ese terreno, con el sentido creativo y con los recursos necesarios para plasmar una letra en una canción pública. "Es mi voz y es mi estilo, mi espada de doble filo /la letra que penetra y desmembrana tus oídos" (LUPE ONE IBARRA, 2017), "afilando el cuchillo a ritmo de este instrumental / pa' que las perras ladren y muevan el culo al ritmo de este rap" (W GXNG, 2017), "aniquilo todo intento por vencerme / destaco por mi rima / derrotando a los imberbes / me encuentro en la cima / mi intelecto no escatima / el poder de mis versos y el encanto de mi rima" (FYLS95, 2010), "bocones se acalambran cuando les escupo rimas" (CHILL A GANG, 2019), y "después de tanto tiempo venimos con buena crema / pa' callar hocicones y enseñarles cómo suena / con un estilo clásico que me corre por las venas" (Obregon, Familia, Klan13, 2020).

El rap como práctica y como acontecimiento adquiere un sentido de importancia para el ejecutor. Por ello las sensaciones que se manifiestan se centran en mantenerlo real, refiriéndose a una coherencia entre lo que se expresa y la realidad experimentada, en un afán por transmitir una percepción de la realidad tal cual es (Riley, 2005).

También se asocia con un sentido en la experiencia de vida: "solo sé que cada verso me inyectan adrenalina / que llega y contamina, mina / como adicto a la heroína" (SICKBRAINCREW SBC, 2020), "mi vida es vacía / hoy la lleno con 
mi ritmo y poesía / mi rap es lo que fluye como sangre por las venas" (Waysones GDB, 2017), y "yo no busco fama compa yo lo hago de cora" (W GXNG, 2017).

El sentido que adquieren las enunciaciones en torno a la práctica del rap es el de mostrarse sincero para con su audiencia y para consigo mismo.

\section{Discusión}

$\mathrm{Al}$ rap como expresión cultural le ha tocado narrar las difíciles condiciones de la vida urbana, en la que el crimen forma parte de lo cotidiano (Presdee, 2004). Resaltar la antisocialidad de sus letras sería una obviedad porque es la naturaleza del subgénero, como en el caso de los narcocorridos. Siguiendo a Valenzuela-Arce (2014), el rap malandro no es mera apología del universo criminal, sino que su producción tiene una función de crónica, registro o diario popular, que vincula las condiciones de la vida urbana popular con eventos de orden moral o ético, rebasando los límites individuales del texto para inscribirse en contextos donde adquiere importancia y significación colectiva. Desde esa óptica, se descifra el rap malandro como una red de sistemas simbólicos, pertenecientes a la tradición del hip hop, que expresan y reproducen procesos importantes de la vida callejera de la ciudad y de su sistema de representaciones, prestando aquí específica atención a aquellos referidos a la masculinidad y trasgresión.

Esto se aúna a que la construcción de la identidad masculina se encuentra atravesada por constantes procesos de violencia contra otros hombres, contra las mujeres y contra sí misma, conocida como la triada de la violencia masculina (Kaufman, 1989). Aquí también se implican situaciones estructurales de violencia, como la marginación, exclusión, desigualdad, y una exposición a un contexto criminógeno previo, lo que lo hace un fenómeno complejo, pues se interconectan diversas formas de violencia que dan soporte a una forma de expresión juvenil. Sin embargo, se considera que la construcción de la cosmovisión del mundo de este estilo musical también plantea importantes cualidades como el orgullo, la reputación, la lealtad, la esperanza, la solidaridad, la honestidad, la reciprocidad, la resistencia y la adaptación, valores que de forma general son muy apreciados en la sociedad moderna.

Además, otra de las características relevantes de los textos analizados es la ruptura moral y lingüística como efecto de la materialidad del rap. De forma similar a las rupturas que crean en el contrato social realidades como la delincuencia, desorganización social, consumo de drogas, el trabajo precario o la violencia y desintegración familiar. Nadie quiere saber de eso porque describen de algún modo la disfuncionalidad de un proyecto de sociedad, pacífico y civilizado. Por eso es 
atacado en lugar de comprendido, pues de algún modo esta forma de expresión tiene algo que decir y cuyo valor empírico no se puede negar.

Así, los principales aportes del rap malandro -que se reproducen en cualquier parte del mundo- son, por un lado, el de socializar los problemas de los barrios y de las ciudades, de hacerlos visibles desde otro punto de vista, el de la cercanía, exposición y atestiguamiento a modo de crónica urbana. Y, por otro lado, el de relatar una parte del mundo (quizá no la mejor) experimentada en un proceso que atraviesa al sujeto y que describe determinadas condiciones de existencia, posibilitando la caracterización de personas, situaciones, relaciones y geografías en crónicas ficticias basadas en la vida real y que pueden ser leídos desde una fenomenología criminológica con enfoque de género, ya que, de algún modo, se plantean formas específicas de vivir la hombría y la violencia urbana.

\section{Referencias}

Arthur, D. (2006). Hip Hop Consumption and Masculinity [conferencia]. The Association for Consumer Research Conference on Gender, Marketing and Consumer Behaviour. Dallas, Texas. https://www.acrwebsite.org/volumes/12504/gender/v08/GCB08

Astorga, L. (1997). Los Corridos de traficantes de drogas en México y Colombia. Revista mexicana de sociología 59(4), 245-261. https://doi.org/10.2307/3541131

Bauman, Z. (2011). Daños Colaterales. Desigualdades sociales en la era global. (L. Mosconi, trad.). Fondo de Cultura Económica.

Bourdieu, P. (1997). Raz̧ones Prácticas. Sobre la teoría de la acción (T. Kauf, trad.). Anagrama.

Cabrera, D. (2009). En torno a la criminología cultural. Nota sobre Jack Katz: "Seductions of crime: moral and sensual attractions in doing evil", Basic Books, New York, 1988. Delito y Sociedad: revista de ciencias sociales, 1(27), 147-154. https://doi. org/10.14409/dys.v1i27.5285

Cáceres, P. (2003). Análisis cualitativo de contenido: una alternativa metodológica alcanzable. Psicoperspectivas, Individuo y Sociedad, 2(1), 53-82.

Canton, D. A. (2006). The Political, Economic, Social, and Cultural Tensions in Gangsta Rap. Reviews in American History, 34(2), 244-257

Carvalho, S. (2010). Criminología Cultural. Perspectiva desde el margen. Delito y Sociedad: revista de ciencias sociales, 2(30), 85-100. https://doi.org/10.14409/dys.v2i30.5622 
Castiblanco, G. (2005). Rap y prácticas de resistencia: una forma de ser joven. Reflexiones preliminares a partir de la interacción con algunas agrupaciones bogotanas. Tabula Rasa, 3, 253-270. https://doi.org/10.25058/20112742.237

CHILL A GANG. (2019, 9 de septiembre). SI LA SACA LA USA Ft. Spooky [video]. YouTube. https://youtu.be/NOZjrWvjykQ

Connell, R. (2003). Masculinidades (I. Artigas, trad.). UNAM-PUEG. (Original publicado en 1995).

Conway, J., Buorque, S. \& Scott, J. (2013). El concepto de género. En M. Lamas (comp.), El Género: la construcción cultural de la diferencia sexual (pp. 21-34). Porrúa.

De Keijer, B. (1997). El varón como factor de riesgo: masculinidad, salud mental y salud reproductiva. En E. Tuñón Pablos (coord.), Género y salud en el sureste de México (pp. 199-219). ECOSUR.

Diez, C. (2016). Feminismos activistas en el Rap Latinoamericano: Mare (Advertencia Lirika) y Caye Cayejera. Ambigua, revista de investigación sobre Género y Estudios Culturales, 3, 39-57.

Doncel de la Colina, J. A. \& Talancón Leal, E. (2017). El Rap Indígena: activismo artístico para la reivindicación del origen étnico en un contexto urbano. Andamios, 14(34), 87111. http://dx.doi.org/10.29092/uacm.v14i34.564

EBK ENT. (2020, 18 de enero). Drimelowcc - Norte De Obregon Ft. Andres CXC [video]. YouTube. https://youtu.be/_rEr8DfCEvM

ENCODAT. (2017). Encuesta Nacional de Adicciones, Drogas, Alcoholy Tabaco. Secretaria de Salud, Comisión Nacional Contra las Adicciones. México.

Fairclough, N. (2008). El análisis crítico del discurso y la mercantilización del discurso público. Discurso y Sociedad, 2(1), 170-185.

Fenwick, M. (2004). New directions in Cultural Criminology. Theoretical Criminology, 8(3), 377-386. https://doi.org/10.1177/1362480604044615

Ferrell, J. (1999). Cultural Criminology. Annual Review of Sociology, 25, 395-418.

Ferrell, J., Hayward, K. \& Young, J. (2008). Cultural Criminology. SAGE.

Foucault, M. (1999). Estética, ética y hermenéutica (A. Gabilondo, trad.). Paidós (original publicado en 1994).

Foucault, M. (2002a). La arqueología del saber (A. Garzón del Camino, trad.). Siglo veintiuno (original publicado en 1969).

Foucault, M. (2002b). Vigilar y Castigar: nacimiento de la prisión (A. Garzón del Camino, trad.). Siglo veintiuno (original publicado en 1975). 
Fouce, J. G. (2003). Música y drogodependencias: análisis de algunos tópicos sobre drogas encontrados en la música. Adicciones, 15(3), 229-242. https://www.adicciones.es/ index.php/adicciones/article/view/430

Frederick, B. \& Larruskain, P. (2015). Cultural Criminology. En W. G. Jennings (ed.), The Encyclopedia of Crime and Punishment. Wiley Blackwell. doi:10.1002/9781118519639. wbecpx103

Fried, C. B. (1999). Who's Afraid of Rap: differential reactions to music lyrics. Journal of Applied Social Psychology, 29(4), 705-721. https://doi.org/10.1111/j.1559-1816.1999. tb02020.x

FYLS95. (2010, 8 de septiembre). Muralla 22 [video]. YouTube. https://youtu.be/wgkOQNUfkfY

García Michel, H. (2019, 27 de febrero). Feli Dávalos y el Rap que se hace en México. Nexos. https://musica.nexos.com.mx/2019/02/27/feli-davalos-y-el-rap-que-se-hace-enmexico

Geertz, C. (2003). La interpretación de las culturas (A. L. Bixio, trad.). Gedisa (original publicado en 1973).

Giménez Montiel, G. (2005). Teoría y Análisis de la Cultura. CONACULTA.

Goffman, E. (2006). Estigma. La identidad deteriorada (L. Guinsberg, trad.). Amorrortu (original publicado en 1963).

Herzfeld, M. (1985). The poetics of manhood: contest and identity in a Cretan Mountain Village. Princeton University Press. https://doi.org/10.2307/j.ctv131bw5r

Hormigos, J. (2012). La sociología de la música: teorías clásicas y puntos de partida en la definición de la disciplina. Revista Castellano-Manchega de Ciencias Sociales, 14, 75-84. http://dx.doi.org/10.20932/barataria.v0i14.102

Hunnicutt, G. \& Andrews, K. H. (2009). Tragic Narratives in Popular Culture: Depictions of Homicide in Rap Music. Sociological Forum, 24(3), 611-636. https://doi. org/10.1111/j.1573-7861.2009.01122.x

Jagodzinski, J. (2005). Music in Youth Culture. A Lacanian Approach. Palgrave Macmillan.

Kaluza, J. (2018). Reality of Trap: Trap Music and its emancipatory potential. IAFOR Journal of Media, Communication \& Film, 5(1), 23-42. https://doi.org/10.22492/ ijmcf.5.1.02

Kaufman, M. (1989). Hombres, placer, poder y cambio. CIPAF, Ediciones Populares Feministas. 
Kubrin, C. E. (2005). Gangstas, Thugs, and Hustlas Identity and the Code of the Street in Rap Music. Social Problems, 52(3), 360-378. https://doi.org/10.1525/ sp.2005.52.3.360

La Squina Loca 662. (2019, 17 de diciembre). TRACK 09.- SALGO CON LA BENDICION / LA SQUINA LOCA / VOL.5 DESDE HERMOSILLO SONORA MEXICO [video]. YouTube. https://youtu.be/0XTjg5z13WQ

LUPE ONE IBARRA. (2017, 10 de agosto). WASLADO MARIHUANO-PROYECTO DE BARRIO// IDEO OFICLAL// [video]. YouTube. https://youtu.be/jbNVQshyDM

Lyng, S. (2004). Crime, edgework and corporeal transaction. Theoretical Criminology, 8(3), 359-375. https://doi.org/10.1177/1362480604044614

Marcial, R. (2006). Aquí puras rolas chidas: música y expresiones juveniles en México. En M. Vizcarra \& A. Fernández (comp.), Disertaciones. Aproximaciones al conocimiento de la Juventud (pp. 199-238). Instituto Jalisciense de la Juventud.

Marcial, R. \& Vizcarra, M. (2017). Puro Loko de Guanatos: masculinidades, violencias y cambio generacional en grupos de esquina de Guadalajara. Universidad de Guadalajara, El Colegio de Jalisco.

Martínez, T. A. (1997). Popular Culture as Oppositional Culture Rap as Resistance. Sociological Perspectives, 40(2), 265-286. https://doi.org/10.2307/1389525

McFarland, P. (2006). Chicano Rap Roots: black-brown cultural Exchange and the making of a genre. Callaloo, 29(3), 939-955. https://doi.org/10.1353/cal.2006.0150

Núñez Noriega, G. (2016). Los estudios de género de los hombres y las masculinidades: ¿qué son y qué estudian? Revista Culturales, 4(1), 9-31. http://culturales.uabc.mx/ index.php/Culturales/article/view/305

Obregon, Familia, Klan13. (2020, 16 de enero). OBREGON// FAMILIA//KLAN13// DE LO PEOR// VIDEO OFICIAL2020 [video]. YouTube. https://youtu.be/ XZubLo3wiBg

Olvera, J. J. (2016). El Rap como economía en la frontera noreste de México. Frontera Norte, 28(56), 85-111.

Orellana Wiarco, O. A. (2012). Criminología Moderna y Contemporánea. Porrúa.

Persaud, J. (2011). The Signature of Hip Hop: a sociological perspective. International Journal of Criminology and Sociology, 4(1), 626-647.

Pitt-Rivers, J. (1968). Honor y categoría social. En J. Peristiany (ed.), El concepto del honor en la sociedad mediterránea (pp. 21-75). Editorial Labor. 
Pond Cummings, A. (2010). Thug Life: hip hop's curious relationship with Criminal Justice. Santa Clara Law Review, 50(2), 515-546. http://dx.doi.org/10.2139/ ssrn.1434838

Presdee, M. (2004). Cultural Criminology: the long and winding road. Theoretical Criminology, 8(3), 275-285. https://doi.org/10.1177/1362480604044609

Reguillo, R. (2000). El lugar desde los márgenes: Músicas e Identidades Juveniles. Revista Nómadas, 13, 40-53. http:// nomadas.ucentral.edu.co/index.php/inicio/36-lasingularidad-de-lo-juvenil-nomadas-13/545-el-lugar-desde-los-margenes-musicas-eidentidades-juveniles

Riley, A. (2005). The Rebirth of Tragedy out of the Spirit of Hip Hop A Cultural Sociology of Gangsta Rap Music. Journal of Youth Studies, 8(3), 297-311. https://doi. org/10.1080/13676260500261892

Ríos, J. C. (2019, 10 de mayo). El Rap del Noro Mexa a través de 15 discos canónicos. Noisey, Vice. https://www.vice.com/es_latam/article/8xzxq4/el-rap-y-el-hip-hop-del-noromexa-a-traves-de-15-discos-canonicos $2 / 48$

Rose, T. (1989). Orality and technology: Rap music and Afro American cultural resistance. Popular Music and Society, 13(4), 35-44. https://doi. org/10.1080/03007768908591371

Rose, T. (2008). The Hip Hop Wars. What we talk about when we talk about hip hop and why it matters. Perseus Books Group.

Rosen, R. M. \& Donald, M. (1999). Comedies of Transgression in Gangsta Rap and Ancient Classical Poetry. New Literaly History, 30(4), 897-928. https:/ /dx.doi. org/10.1353/nlh.1999.0051

Rubin, G. (1986). El tráfico de mujeres. Notas sobre la economía política del sexo. Nueva Antropología, 8(30), 95-145.

Schneider, C. (2011). Culture, Rap Music, "Bitch", and the Development of the Censorship Frame. American Behavioral Scientist, 55(1), 36-56. https://doi. org $/ 10.1177 / 0002764210381728$

Schott, D. F. (2015). La Producción Cultural de Bocafloja como reflejo de las identidades complejas en un mundo globalizado [tesis de Maestría, University of North Carolina Wilmington].

SICKBRAINCREW SBC. (2020, 7 de mayo). PROBLEMAS FT. FARK X BAGONM (Video Oficial) 2020 [video]. You'Tube. https://youtu.be/d7PkQq18C9Q

Silva, D. A. (2017). “Somos las vivas de Juárez": hip-hop femenino en Ciudad Juárez. Revista Mexicana de Sociología, 79(1), 147-174. 
Tickner, A. B. (2008). Aqui en el Ghetto: Hip-hop in Colombia, Cuba, and Mexico. Latin American Politics and Society, 50(3), 121-146. https://doi.org/10.1111/j.15482456.2008.00024.x

Tonkonoff, S. (2011). Prohibición, transgresión, castigo. Notas para una criminología cultural. Alegatos, 79, 741-758.

Trajtenberg, N. (2011). Culture and Emotions in Cultural Criminology: an alternative criminological explanation? [Disertación de Maestría en Filosofía en Criminología, University of Oxford] http://nacvi.cienciassociales.edu.uy/wp-content/ uploads/2015/05/2011-trajtenberg.pdf

Turner, M. (2019). Hip Hop as Cultural Capital: remixing Bourdieu's theory to affirm cultural wealth. Languaje, Literature and Interdisciplinary Studies, 2(3), 85-100.

Valdés Castellanos, G. (2015). Historia del narcotráfico en México. Penguin Random House.

Valenzuela-Arce, J. M. (2004). Género y repertorios identitarios. En A. de la Torre, R. Ojeda, \& C. Maya (coord.), Construcción de género en sociedades con violencia (pp. 39-51). Universidad de Sinaloa-Porrúa.

Valenzuela-Arce, J. M. (2014). Jefe de jefes: corridos y narcocultura en México. El Colegio de la Frontera Norte.

Vallejo, J. P. (2010). La disipada historia de la maribuana en México: 1492-2010. Eterno Femenino Ediciones.

W GXNG. (2017, 22 de septiembre). 7 - A trecientos cuarenta - Dobleu Clicka ft Pk Crew $\backslash$ Enfermos Crew [video]. YouTube. https://youtu.be/uFARSiBmyM8

Waysones GDB. (2017, 14 de enero). Waysones GDB FT Malandro Recordz - MI ZONA VIDEO OFFICIAL [video]. YouTube. https://youtu.be/sGw3rPY_Mds

Young, J. (2015). La Imaginación Criminológica (A. Gavela Gimeno, trad.). Marcial Pons (original publicado en 2011). 